The substance possessed acid properties, a dilute solution in chloroform was yellowish green-coloured and showed by itself no definite absorption bands (absorption from $\pm 470 \mathrm{~m} \mu$ down to the lower part of the spectrum). With the Carr and Price reagent a violet colour developed with absorption bands at 525-535 $\mathrm{m} \mu$ and at 590-620 $\mathrm{m} \mu$. The 525-535 $\mathrm{m} \mu$ band rapidly decreased, the reaction mixture turned blue to greenish blue and a band at $670-690 \mathrm{~m} \mu$ became visible. The bands at 590-620 mu and at $670-690 \mathrm{~m} u$ and also the blue colour are relatively stable. The Lovibond value of the yellow substance was 75,000 (Wolff) or blue value 15,000 . From $15 \mathrm{gm}$. of fatty acids a few milligrams of the yellow product were obtained.

Different samples of cod liver oil and halibut liver oil acids showed this reaction with the antimony trichloride reagent. It was not observed with the acids of butter fat or arachis oil, or with carotene, cholesterol or ergosterol.

Further investigations are in progress.

Laboratory of Hygiene,

A. EMmarie.

University of Utrecht. June 20.

1 Dann and Moore, Biochem. J., 27, 1166; 1933.

- Dann, Booth, Golding and K̈on, Biochem. J., 29, 138; 1935. adisbury, Morton and Lovern, Biochem. J., 27, 1451 ; 1933.

4 Edisbury, Morton and Lovern, Biochem. J.' 29 , '899; 1935.

s Gillam, Heilbron, Hilditch and Morton, Biochem. J., 25, 30; 1931.

\section{The Metabolism of Retina}

SIGNIFICAN'T differences of the normal metabolism of tissues either in Ringer bicarbonate or in phosphate solution have so far not been reported ${ }^{1,2}$. On the other hand, the contradictory results obtained by Dixon and Elliot ${ }^{3}$ and Alt ${ }^{4}$ respectively concerning the hydrogen cyanide stable residue of the respiration of liver slices have been explained by the use of different media. Nearly complete inhibition occurs in Ringer bicarbonate while a considerable residue remains in phosphate solution or in Ringer without bicarbonate.

The study of the metabolism of retina and tumours has shown the following results :

The respiration of rat's retina and Crocker mousesarcoma 189 in bicarbonate Ringer is about twice as high as in phosphate Ringer.

\begin{tabular}{|l|c|c|} 
& \multicolumn{2}{c}{$Q_{0,}$} \\
\hline in bicarb. & in phosphate \\
\hline Retins & 32 & $17 \cdot 5$ \\
\hline Tumour & $12-18$ & $6-9$ \\
\hline
\end{tabular}

While the respiration of the tumour is inhibited in both media by about 90 per cent by hydrogen cyanide $n / 1,000-n / 500$, the respiration of retina is inhibited by

Retina, hydrogen cyanide $n / 1000$

\begin{tabular}{|l|c|c|c|}
\hline & $Q_{\mathrm{O}_{2}}$ & $Q_{\mathrm{M}}^{\mathrm{O}_{2}}$ & $Q_{\mathrm{M}}^{\mathrm{N}_{\mathrm{M}}}$ \\
\hline Bicarb. & $32-35$ & 88 & 88 \\
Phosphate & 3 & - & - \\
\hline
\end{tabular}

the same hydrogen cyanide concentrations only in phosphate Ringer but not inhibited at all in bicarbonate Ringer. The Pasteur reaction in this case is completely inhibited, the wobic glycolysis becomes equal to the anærobic. Hydrogen cyanide, therefore, in bicarbonate media acts on retina as ethylcarbylamine $^{5}$ on other glycolysing tissues. The anærobic glycolysis is not affected. The inhibiting effect of phosphate and of hydrogen cyanide in phosphate on the respiration is reversible.

The natural thickness of the retina allows the measurement of its respiration at very low oxygen tensions. In nitrogen with 5 per cent oxygen, the respiration in phosphate remains still normal $\left(Q_{\mathrm{O}_{2}}=17 \cdot 5\right)$ and under our experimental conditions 95 per cent carbon monoxide with 5 per cent oxygen leads to no inhibition of the respiration of the retina.

Molteno Institute,

H. LASER.

University of Cambridge. June 30 .

\footnotetext{
1 O. Meyerhof, "Die chemischen Vorgănge im Muskel.", p. 53. (Springer, Berlin, 1930.)

2 F. Dickens and F. Simer, Biochem. $J, 25,985 ; 1931$

3 M. Dixon and K. A. C. Elliot, Biochem. J., 23, 812 ; 1929.

H. I. Alt, Biochem. Z., 221, 498; 1930.

- O. Warburg, Biochem. Z., 172, 432 ; 1926.
}

\section{Coagulation of the Blood as a Chain Reaction}

WITH reference to the letter of Dr. Albert Fischer published in NaTuRE of June $29(135,1075)$, readers of this journal may be interested to be reminded of the following quotation from a paper by C. Delezenne, published in Ann. de Physiol. et de Physicochim. biologique $(2,537 ; 1926)$ :

"Outre la faculté essentielle qui le définit, le fibrinferment possède encore la curieuse propriété, découverte par Border et Gengou, de faire luimême naître le fibrinferment, ou tout au moins d'en accélérer considérablement la production, lorsqu' on l'ajoute à un milieu qui en renferme tous les générateurs."

This sentence and what follows it fully substantiate the theory of blood coagulation as a chain-reaction described by Dr. Fischer.

Department of Veterinary Physiology,

Hans J. Fuchs. University of Berlin, Berlin, N.W.7. June 29.

\section{Fish and Rabbit Liver Glycogens}

LIVER glycogen from fish of the genus Gadidoe, first isolated and described by Bell and Young ${ }^{1}$, was subjected to methylation by the procedure of Haworth and Percival ${ }^{2}$. The product showed a methoxyl content of $45 \cdot 5$ per cent (maximum) and was identical with the corresponding derivative from highly purified rabbit liver glyoogen in all its properties including $[\alpha]_{D}$ in water $+208^{\circ}$ and in chloroform $+209^{\circ}$. Hydrolysis with a mixture of aqueous hydrochloric and acetic acids, followed by separation of the cleavage products, yielded an amount of analy. tically pure tetramethylglucopyranose corresponding to $9 \cdot 1$ per cent of the starting material, while control experiments on methylated rabbit liver glycogen gave $\mathbf{9 . 5}$ per cent. Both these values correspond to a molecular magnitude of 12 glucose units for the glycogen molecule, and are in agreement with the findings of Haworth and Percival for commercial rabbit liver glycogen. The methylated glycogens are 